\title{
A INTRODUÇÃO DA ABORDAGEM PARAMÉTRICA NO ENSINO DE PROJETO ARQUITETÔNICO: RELATO DE UMA EXPERIÊNCIA
}

\author{
THE INTRODUCTION OF THE PARAMETRIC APPROACH IN \\ ARCHITECTURAL DESIGN EDUCATION: AN EXPERIENCE REPORT
}

\author{
Neliza Maria e Silva Romcy ${ }^{1}$ \\ Universidade Federal do Ceará, Fortaleza, CE, Brasil, nelizaromcy@dau.ufc.br \\ Daniel Ribeiro Cardoso ${ }^{2}$ \\ Universidade Federal do Ceará, Fortaleza, CE, Brasil, danielcardoso@ufc.br
}

\begin{abstract}
Resumo
Diante das discussões contemporâneas sobre a aplicação dos meios digitais mais recentes na atividade projetual, o presente artigo tem como objetivo contribuir para a compreensão de estratégias para introduzir o processo paramétrico de projeto no ensino de projeto arquitetônico. Considerando levantamento teórico e prático, parte-se da hipótese de que apenas o ensino tutorial de ferramentas não é o suficiente para uma aprendizagem do processo paramétrico em todo o seu potencial, sendo necessário vislumbrar um percurso didático que inclua tanto uma mudança de olhar sobre o objeto projetado, quanto a própria atividade projetual. Apresenta-se e discute-se aqui um dos experimentos pedagógicos realizados na etapa de validação da pesquisa - um curso de extensão de 40 horas, desenvolvido na Universidade Federal do Rio Grande do Norte, com registro do processo e coleta de dados junto aos participantes. O curso incluiu noções introdutórias sobre o tema, exercícios de criação com ferramenta paramétrica e atelier de projeto. As atividades de atelier envolveram o desenvolvimento de um bicicletário em equipe, com realização de brainstorm, desenvolvimento da proposta e apresentação dos produtos finais. Como resultado, percebe-se que, apesar dos participantes não apresentarem experiência prévia com o tema, os processos e produtos são foram satisfatórios, com o desenvolvimento e investigação de algoritmos complexos, além do reconhecimento do potencial da modelagem paramétrica, associada a práticas reflexivas em atelier. Os principais desafios incluem as mudanças da lógica projetual habitual, extrapolando o uso da ferramenta. Observou-se a importância de se introduzir a abordagem paramétrica no ensino para além de experimentos didáticos isolados, distribuída coerentemente com a estrutura curricular dos cursos, demandando a identificação das áreas de conhecimento em que o tema pode ser inserido.
\end{abstract}

Palavras-chave: Modelagem Paramétrica. Processo de Projeto. Ensino de Projeto.

\begin{abstract}
This paper aims to contribute to the understanding of strategies to introduce the parametric design in architectural design teaching. Contemporary discussions on the application of the most recent digital tools in design are considered. Based on a theoretical and practical review, the hypothesis cogitates that only tutorial teaching of tools is not enough to parametric design learning to its full potential, and it is necessary to preview a didactic approach that includes both a change of perspective on the designed object, as well as the design activity itself. A pedagogical experiment is presented and discussed - a 40-hour extension course, applied in Federal University of Rio Grande do Norte, during the research validation stage, including the registration of the whole process and data collection with the participants. The course contained an introductory basis on the subject, design exercises with parametric tools and studio activities. The studio activities involved the design of a bicycle rack, with the participants divided into teams, brainstorming for initial concept, the design of solutions and discussion of the final proposals. The results demonstrate that, although most participants had no previous experience with the subject, the processes and products were satisfactory, including the creation and investigation of complex algorithms, besides the recognition of the potential of parametric modeling, associated to reflexive practices in the studio. The main challenges include the changes in the usual design logic, extrapolating the use of the tool. It was observed the importance of introducing the parametric approach in teaching besides isolated didactic experiments, distributed coherently with the curricular structure of the courses, demanding the identification of the areas of knowledge in which the subject can be inserted.
\end{abstract}

Keywords: Parametric Modeling; Design Process; Design Teaching.

How to cite this article:

ROMCY, Neliza Maria e Silva; CARDOSO, Daniel Ribeiro. A introdução da abordagem paramétrica no ensino de projeto arquitetônico: relato de uma experiência. PARC Pesquisa em Arquitetura e Construção, Campinas, SP, v. 10, p. e019018, abr. 2019. ISSN 1980-6809. Disponível em: <https://periodicos.sbu.unicamp.br/ojs/index.php/parc/article/view/8652271>. Acesso em: 26 abr. 2019. doi:https://doi.org/10.20396/parc.v10i0.8652271. 


\section{Introdução}

A busca por novas estruturas no ensino de projeto se dá principalmente devido aos impactos pedagógicos do que Oxman (2005, p. 229) coloca como "projeto digital" (digital design). Segundo a autora, o "projeto digital" se refere às práticas de projeto apoiadas em novas tecnologias, que trazem especificidades em suas metodologias, formas de interação projetual e conteúdo formal. Nesse cenário, destaca-se o modelo paramétrico, que consiste na representação computacional de um objeto construído com entidades, cujos atributos podem ser fixos ou variáveis. Os atributos variáveis podem ser representados por parâmetros e regras, de forma a permitir que objetos sejam automaticamente ajustados de acordo com o controle do usuário e a mudança de contexto (ANDRADE; RUSCHEL, 2009).

Diante das novas possibilidades, que extrapolam descrições gráficas de representação e visualização, tornou-se necessária a reflexão sobre as especificidades da abordagem paramétrica para sua inserção no ensino de projeto, considerando novas propostas didáticas. Assim, surgiu a questão de como introduzir, no ensino de projeto, o uso de processos e ferramentas computacionais que desenvolvam o objeto a partir de parâmetros.

Nesse contexto, o presente artigo tem como objetivo contribuir para a compreensão de estratégias para introduzir o processo paramétrico de projeto no ensino de projeto arquitetônico. Seu conteúdo é parte de uma pesquisa que, além das etapas de embasamento teórico e levantamento de referências práticas, realizou experimentos pedagógicos de curta e longa duração em duas instituições de ensino superior para investigar a hipótese de que apenas o ensino tutorial de ferramentas não é o suficiente para uma aprendizagem do processo paramétrico em todo o seu potencial - sendo necessário vislumbrar um percurso didático que inclua tanto uma mudança de olhar sobre o objeto projetado, quanto a própria atividade projetual. Com esse objetivo, os experimentos didáticos tratam de desenvolver e aplicar desde materiais didáticos e exercícios que abordem a mudança de ferramenta/lógica na descrição de um objeto, até exercícios de projeto, em que o modelo paramétrico possa colaborar na solução de um problema projetual.

Apresenta-se e discute-se, nesse artigo, um dos experimentos pedagógicos realizados, considerado de média duração: um curso de extensão de 40 horas, desenvolvido na Universidade Federal do Rio Grande do Norte (UFRN), com registro de todo o processo e coleta de dados junto aos participantes. $O$ curso de extensão, que reúne estudantes, professores e profissionais de arquitetura e urbanismo, teve como objetivo testar estratégias pedagógicas aplicadas fora de um componente curricular convencional da formação profissional. Assim, o experimento a ser apresentado permitiu verificar como os participantes se apropriaram da abordagem paramétrica, considerando a metodologia adotada para o curso, tanto a partir dos exercícios de modelagem, quanto com o uso do modelo paramétrico durante a atividade projetual, em atelier.

\section{Fundamentação teórica: abordagem paramétrica e ensino de projeto}

Diferente de um modelo tridimensional estático, um modelo paramétrico pode ser considerado como um sistema dinâmico de relações entre objetos. Assim, a maior alteração do Projeto Auxiliado por Computado (Computer Aided Design - CAD) tradicional para a modelagem paramétrica é a possibilidade de interação entre o usuário e o modelo (FLORIO, 2012). 
Durante a modelagem paramétrica, o processo se desenvolve através do entendimento da relação entre as partes, no intuito de criar respostas emergentes a essas relações. Esse comportamento emergente pode retroalimentar a própria proposição inicial do problema, gerando soluções diversas, porém ainda adequadas, e possibilitando a chamada arquitetura com potencial generativo. A ênfase muda do "fazer a forma" (making of form) para "encontrar a forma" (finding of form) (KOLAREVIC, 2003; SOARES; TRAMONTANO, 2012).

Ressalta-se, porém, que a capacidade para a geração de novos modelos é altamente dependente das habilidades perceptivas e cognitivas do projetista, através de processos dinâmicos de interpretação e manipulação do modelo computacional. A repercussão automática das mudanças por todo o modelo, assim como as alternativas a serem geradas, dependerão das restrições impostas pelo projetista, cabendo a ele explorar as alternativas e julgar qual a mais viável dentro do contexto projetual. Cada problema pode apresentar uma infinidade de soluções adequadas, porém diferentes entre si. Nesse processo sistêmico, pode-se considerar, ainda, a inserção de parâmetros externos, dentro da abertura existente no sistema para imprevisibilidades (FLORIO, 2012; KOLAREVIC, 2001; SOARES; TRAMONTANO, 2012).

Diante da complexidade e diversidade dos fatores que envolvem o processo de projeto paramétrico, o trabalho colaborativo em equipe pode ser um fator diferencial para potencializar o pensamento criativo e quanto mais complexo for o projeto, mais profissionais com diferentes expertises devem estar envolvidos (LAWSON, 2011). É o que também defende Oxman (2010) em seu manifesto sobre o novo estruturalismo, para quem arquitetos, engenheiros e "fabricadores" devem trabalhar juntos desde as etapas iniciais do projeto. Diante desse contexto, questiona-se se os cursos de arquitetura e design estão formando profissionais com esses perfis e habilidades, em especial para o desenvolvimento do projeto colaborativo, pautado em uma abordagem sistêmica e reflexiva.

A observação de casos práticos tem demonstrado que algumas escolas no Brasil e América Latina estão começando a aplicar software para projeto paramétrico, BIM e prototipagem rápida. A questão essencial é que esses programas nem sempre são introduzidos em conjunto a uma reflexão teórica e projetual e acabam sendo pensados como ferramenta, não como meio (ROCHA, 2009).

Para compreender as especificidades da abordagem paramétrica na atividade projetual, é importante considerar a lista colocada por Woodbury (2010, p. 24) das habilidades que os projetistas devem desenvolver para aplicar a modelagem paramétrica de maneira efetiva: (i) Conceber como ocorrem fluxos de dados; (ii) Dividir o projeto em partes, garantindo a interação entre elas ao longo do processo; (iii) Nomear as partes para facilitar a comunicação; (iv) Pensamento abstrato; (v) Pensamento matemático; (vi). Pensamento algorítmico. O autor ressalta que algumas dessas habilidades, como os pensamentos abstrato e matemático, já são familiares aos projetistas, porém outras são completamente novas e devem ser vislumbradas pelas novas estratégias de ensino projetual.

Em experiências didáticas realizadas na disciplina de Projeto 3 do curso de Arquitetura e Urbanismo do Instituto de Arquitetura e Urbanismo da Universidade de São Paulo (IAU-USP), Nojimoto, Tramontano e Anelli (2011) também buscaram compreender o processo de concepção, a partir da lógica paramétrica e da fabricação digital. Com a realização de atividades em atelier, os autores verificaram que, enquanto algumas equipes se dispuseram a enfrentar o desafio da definição de parâmetros e procedimentos lógicos para a formulação de uma geometria que correspondesse a suas 
intenções projetuais, outras definiram uma geometria complexa apenas pela capacidade de processamento do Rhinoceros, partindo de uma intenção formal inicial, e não das possibilidades de relação entre os elementos.

Nessa situação, soma-se que os estudantes costumam apresentar experiências prévias apenas com meios de representação em desenho e CAD tradicional, onde o foco é a representação da forma final, descrita geometricamente. Por outro lado, como já mencionado, o método paramétrico força uma representação processual prévia através do algoritmo, em que a forma é resultado desse processo.

Em um cenário internacional, com enfoque em Portugal, Beirão (2017) também coloca que a formação atual dos projetistas em novas tecnologias e ferramentas digitais está muito aquém do ideal. $O$ autor ressalta que uma educação avançada nessa área constitui uma mais-valia muito especial quando comparada à formação tradicional, pois garante profissionais inovadores e mais adequados aos problemas que a sociedade futura apresenta (sustentabilidade, smart cities, dentre outros).

Durante pesquisas sobre a introdução de novas tecnologias no ambiente pedagógico, Sedrez e Celani (2014) apontam o potencial da abordagem "Aprendizagem Baseada em Projetos" ou "Aprendizagem Baseada em Problema" (Problem ou Project Based Learning) para se trabalhar as questões do ensino de projeto contemporâneo. A metodologia parte de uma questão ou desafio proposto aos estudantes, criando a necessidade de se conhecer o conteúdo, adquirir habilidades, e praticar a colaboração e a comunicação, em processos de avaliação que observam o pensamento crítico reflexivo, à maneira enunciada por Schön (2000). Assim, propor uma estruturação bem justificada da maneira de como resolver o problema faz parte do processo de aprendizagem e cria oportunidades para a inovação.

Assim, para a introdução da abordagem paramétrica no ensino de projeto, percebe-se que, bem além da capacitação em software específicos, é necessária uma mudança de olhar sobre o objeto projetado, a partir da compreensão da forma como expressão de uma lógica pré-definida e a visão do processo como sistêmico, em que a definição de relações e interações repercute na geração do produto final. Neste caso, o experimento apresentado a seguir parte dessa hipótese para propor e avaliar estratégias pedagógicas que poderiam mediar o ensino/aprendizado do projeto baseado em parâmetros. Soma-se, ainda, a inclusão da atividade projetual em atelier como fundamental para a prática do trabalho colaborativo, a "Aprendizagem Baseada em Problema" e exercício do "pensamento crítico reflexivo".

\section{Método}

A pesquisa é do tipo qualitativa e de caráter exploratório, ou seja, visa ao aprimoramento de ideias ou à descoberta de intuições (GIL, 2002). Na abordagem qualitativa, a pesquisa tem o ambiente como fonte direta dos dados, diferindo da abordagem quantitativa pelo fato de não utilizar dados estatísticos como o centro do processo de análise de um problema. Os dados coletados nessas pesquisas são descritivos, retratando o maior número possível de elementos existentes na realidade estudada e nelas preocupa-se mais com o processo do que com o produto (PRODANOV; FREITAS, 2013).

Além de considerar a fundamentação teórica, o experimento didático em análise no presente artigo também considera resultados de atividades anteriores desenvolvidas durante a pesquisa. Trata-se de um curso de extensão introdutório de 20 horas, realizado na Universidade Federal do Ceará junto ao Laboratório de Ensino, Pesquisa e Extensão em Projeto Digital da UFC (LED-UFC). Por se referir a um curso introdutório de 
curta duração, esse experimento didático de 20 horas não apresentou atividade em atelier. Seu principal objetivo incluiu a aplicação de material didático e exercícios, com foco na ferramenta e na compreensão da lógica paramétrica, possibilitando uma posterior coleta de dados com os participantes, que também incluíram estudantes e profissionais (ROMCY, 2016).

Como principal contribuição desse experimento didático anterior, destaca-se que, além de exercícios introdutórios sobre ferramentas de programação visual, devem ser previstas atividades que envolvam a leitura e descrição lógica dos objetos a serem modelados, desenvolvendo a capacidade do projetista de reconhecer suas características fixas/variáveis e estruturar sua descrição a partir de algoritmos e possíveis parâmetros.

No caso aqui discutido, a pesquisa realizada incluiu observação e registro da aplicação de um curso de extensão, análise do resultado dos trabalhos e aplicação de questionário junto aos participantes ao final do processo. Antes do curso propriamente dito optouse, ainda, por organizar uma palestra sobre o tema na instituição, como estratégia de divulgação, verificação de demanda e início de debate. A palestra, intitulada "O projeto paramétrico aplicado à arquitetura e design”, contou com um público de 32 ouvintes.

A programação da palestra teve duração de duas horas, abordando: (i) Introdução ao projeto paramétrico, incluindo conceitos, ferramentas e processos; (ii) Apresentação de exemplos aplicáveis nas áreas de arquitetura e design; (iii) Dúvidas, comentários e debate. Ao final da palestra, houve divulgação do curso de extensão e e-mail para préinscrição. As dúvidas colocadas ao final para debate foram voltadas para aplicações e software específicos, incluindo: a) exemplos de software voltados para simulação em conforto e se a presente pesquisa envolvia este tema; b) software paramétricos utilizados na área da engenharia civil; c) diferenças entre o Grasshopper (Scott Davidson) e o Dynamo (Autodesk); d) debate sobre obras que utilizassem a fabricação digital na execução final.

Após a divulgação, o curso de extensão foi proposto no período das férias, realizado no Laboratório de Informática (LabInfo) da UFRN, contando também com o apoio dos professores do Laboratório de Maquetes (LabMaq), que acompanharam todo o processo.

Foram previstas 20 vagas, divididas entre profissionais (10 vagas) e estudantes de graduação (10 vagas), exigência estabelecida pela ação de extensão. O curso incluiu desde noções introdutórias sobre o tema, exercícios com ferramenta/lógica paramétrica, até sua aplicação em projeto. A programação prevista dividiu a carga horária (40 horas) nas seguintes atividades: a) introdução teórica com apresentação de conceitos e exemplos, além da apresentação do ambiente de trabalho da ferramenta (4 horas); b) introdução à ferramenta com exercícios passo-a-passo (8 horas); c) aprofundamento no uso da ferramenta e lógica paramétrica com exercícios de leitura de um objeto pré-determinado e posterior desenvolvimento do algoritmo (8 horas); d) início de atividade projetual: apresentação do tema (bicicletário no campus da UFRN), divisão de equipes e brainstorm (4 horas); e) apresentação parcial das propostas e discussão coletiva dos algoritmos (4 horas); f) atelier com orientação por equipe/ desenvolvimento de modelos físicos (8 horas); g) discussão final das propostas com auxílio dos modelos e avaliação final do curso (4 horas).

A seguir, será analisada a experiência de realização desse curso, composto de 10 aulas (4 horas/aula) distribuídas ao longo de nove dias, com base nos dados coletados a partir da observação em sala de aula, dos resultados dos trabalhos em atelier e da aplicação de questionários junto aos participantes. 
A estrutura do questionário foi composta por três blocos: (i) Caracterização do participante; (ii) Atividades do curso; (iii) Modelagem paramétrica.

As questões de caracterização do participante incluíram as seguintes opções: projetista, docente, mestrando, doutorando ou estudante de graduação, com indicação de curso e semestre. Perguntou-se, ainda, se o participante possuía alguma experiência anterior com modelagem paramétrica.

As questões sobre as atividades do curso solicitavam que o participante marcasse um valor de 0 a 10 para avaliar a contribuição que cada atividade apresentou para o seu aprendizado sobre a modelagem paramétrica. Estipulou-se que fosse considerado o como "nenhuma contribuição" e 10 como "contribuição fundamental". Como lista de atividades foram colocadas:

1. Apresentação inicial de conceitos e exemplos de aplicação na arquitetura e design.

2. Desenvolvimento do algoritmo passo-a-passo, com a explicação geral de cada componente.

3. Apresentação da lógica geral do algoritmo e aplicação em exemplos, antes do desenvolvimento passo-a-passo.

4. Apresentação do objeto para que os participantes tentassem descrever a sua lógica de formação através de desenhos esquemáticos.

5. Atividade de desenvolvimento de projeto em equipe, para que os participantes buscassem aplicar a modelagem paramétrica em uma situação prática.

6. Desenvolvimento de modelos físicos através de equipamentos de fabricação auxiliado por computador.

Considerando que não foi possível fabricar modelos físicos satisfatórios por nenhuma das equipes, o item 6 não foi considerado na análise.

As questões sobre a modelagem paramétrica incluíram três questões discursivas que abordavam, separadamente, as pretensões de uso no futuro, as dificuldades percebidas durante o curso e sugestões.

Para a interpretação dos dados, foram utilizados os seguintes procedimentos: análise quantitativa para as questões objetivas dos blocos 1 e 2 (Caracterização do participante e Atividades da disciplina) e análise de conteúdo para as questões subjetivas do bloco 3 (Modelagem paramétrica).

\section{A experiência didática}

Em termos gerais, o curso foi organizado em duas etapas: 1. Introdução à modelagem paramétrica ( $20 \mathrm{~h}) ; 2$. Aplicação da abordagem paramétrica em projeto, com atividade em atelier $(20 \mathrm{~h})$.

A introdução à modelagem paramétrica contou com a apresentação de conceitos e exemplos, seguida do desenvolvimento de exercícios, envolvendo a ferramenta e as mudanças na lógica de descrição de um objeto parametricamente. Nesta etapa, a proposta didática partiu de um ensino tutorial, com a construção do algoritmo passo-apasso e explicação dos diferentes componentes/comandos, até uma maior discussão sobre a abordagem paramétrica, em que se exercitou com os participantes a dedução e descrição da lógica compositiva de obras relacionadas aos modelos paramétricos estudados, antes da construção do algoritmo propriamente dito. Nesse caso, ressaltou- 
se a importância de se compreender o objeto a partir de uma visão sistêmica, com foco no entendimento da relação entre as partes para a geração de respostas emergentes.

Para a etapa de aplicação da abordagem paramétrica em projeto com atividade em atelier, foi utilizada como referência a "Aprendizagem Baseada em Problemas". Foi colocado um problema projetual inicial, os participantes foram divididos em equipe para a discussão e desenvolvimento de soluções, com a utilização do modelo paramétrico.

Os exercícios da primeira etapa, envolvendo ferramenta e descrição lógica, foram distribuídos em nove modelos paramétricos, que abordam desde tópicos introdutórios, como elementos básicos de geração da forma (ponto, linhas, planos, superfícies) e operações de transformação (rotação, translação, escala), até um maior nível de complexidade, como manipulação de dados (série, listas, árvores de dados).

Como material didático, os algoritmos de cada modelo foram organizados e impressos em folha A4 para serem consultados pelos participantes durante as aulas. Além do algoritmo de cada modelo, os componentes foram descritos em legendas, com seu nome e função. A Figura 1 exemplifica este material didático de apoio com o algoritmo gerado para o Exercício 1 e a descrição de seus componentes para facilitar a compreensão dos participantes. Optou-se por não incluir as imagens processuais, com as etapas do modelo sendo construído, porque aumentaria consideravelmente o volume de impressão em um curso gratuito. Como alternativa, as etapas de construção foram mostradas a partir do próprio modelo paramétrico em sala de aula.

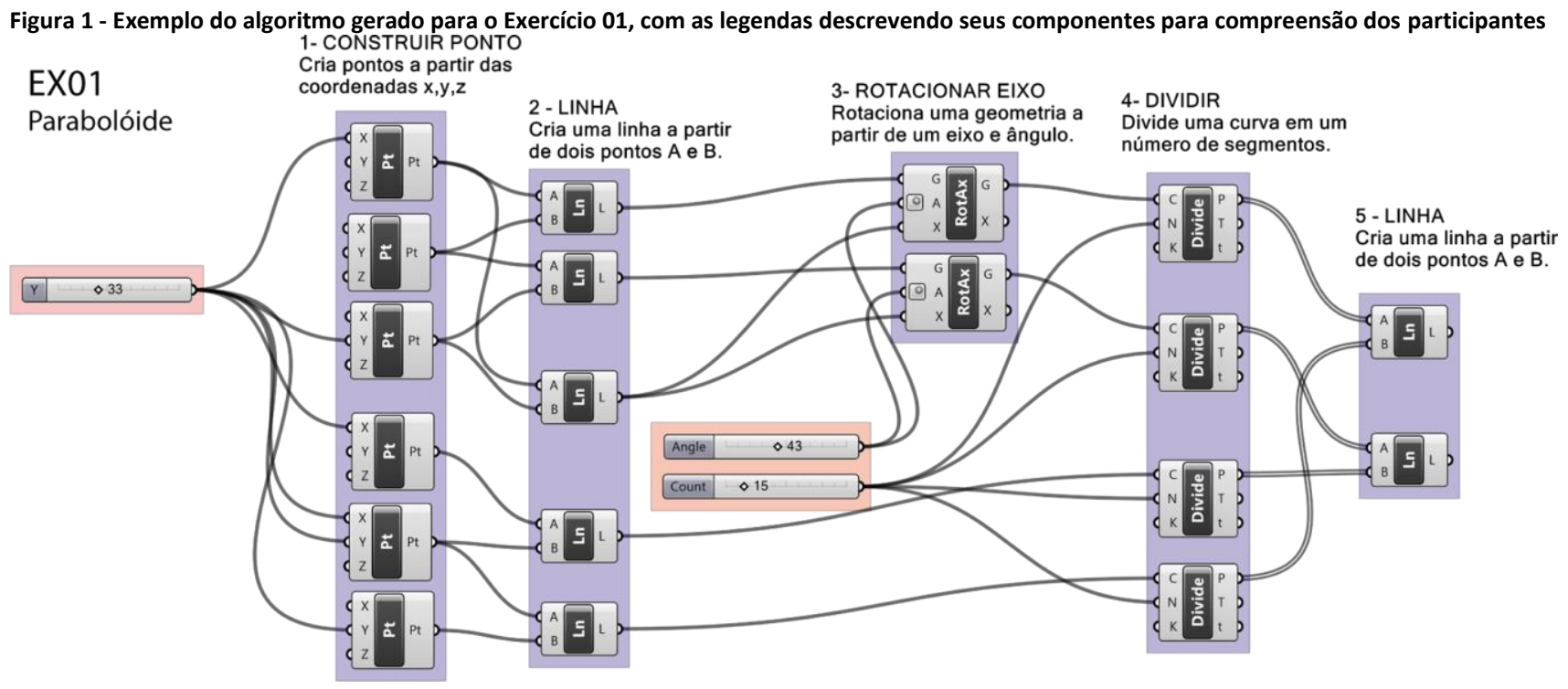

Fonte: Os autores.

O curso teve início com a apresentação dos participantes, incluindo perfil, experiências anteriores e expectativas. Houve uma aula expositiva com o mesmo conteúdo apresentado na palestra, para revisão dos conceitos e possibilidades de aplicação, seguida da introdução ao ambiente de trabalho do software Rhinoceros e seu plug-in Grasshopper.

A seguir, são apresentados os modelos utilizados ao longo dos nove exercícios, ressaltando-se sua importância para o processo de aprendizagem durante a primeira etapa do curso.

Os exercícios 01 e 02 incluíram o desenvolvimento de superfícies regradas - um paraboloide e um hiperboloide (Figura 2). O procedimento didático para estes exercícios consistiu em construir cada algoritmo passo-a-passo, junto aos participantes, 
explicando a função de cada componente, considerando que se tratam dos elementos básicos de geração da forma (ponto, linhas, planos, superfícies).

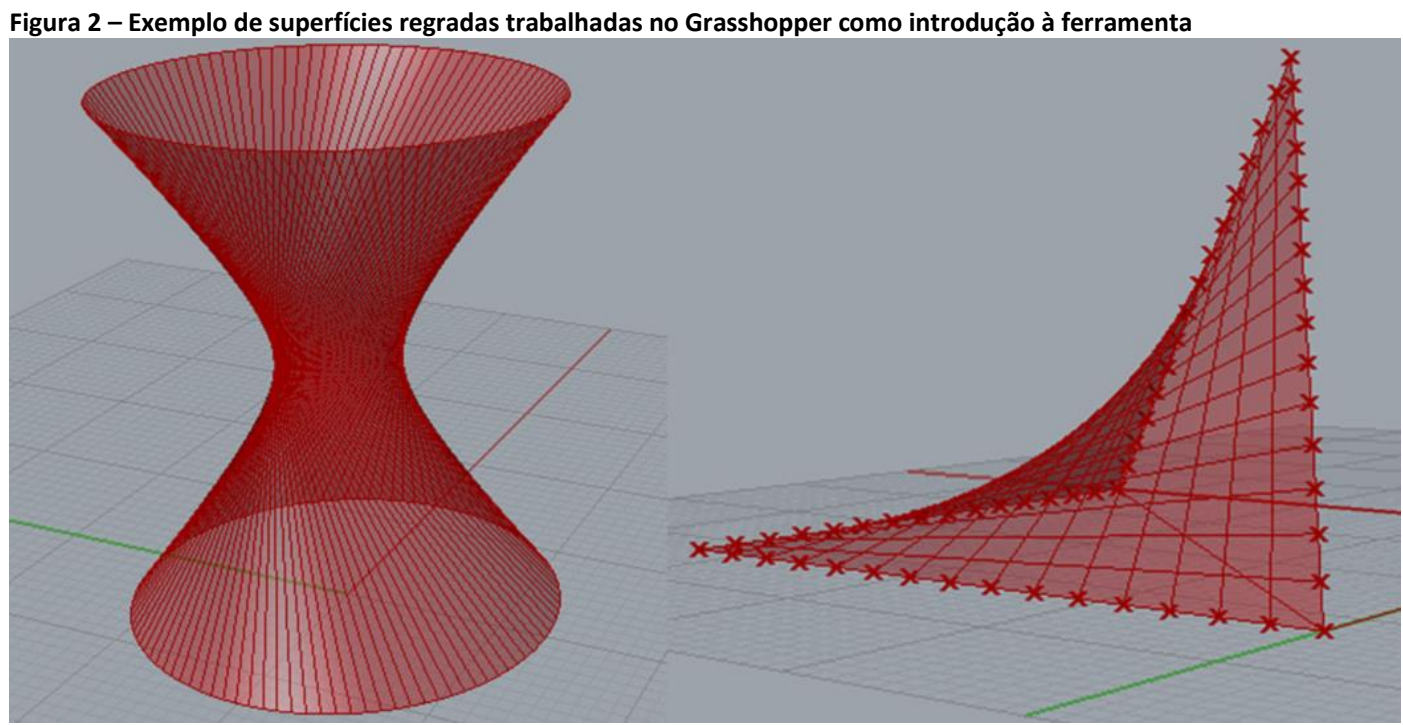

Fonte: Os autores.

Além da sua existência em repertório arquitetônico através de estruturas em casca ou tensoestruturas, a escolha de iniciar o curso com superfícies regradas considera que sua construção lógica permite uma relação explícita de como os elementos geométricos básicos de ponto, linha e plano podem ser construídos e manipulados por meio do algoritmo e representados em modelo paramétrico. Assim, buscou-se tornar didaticamente mais claro aos participantes como se estabelece a relação entre geometria, algoritmo e modelo paramétrico.

Figura 3 - Imagens do exercício 04 , contendo o processo ilustrado da construção da forma

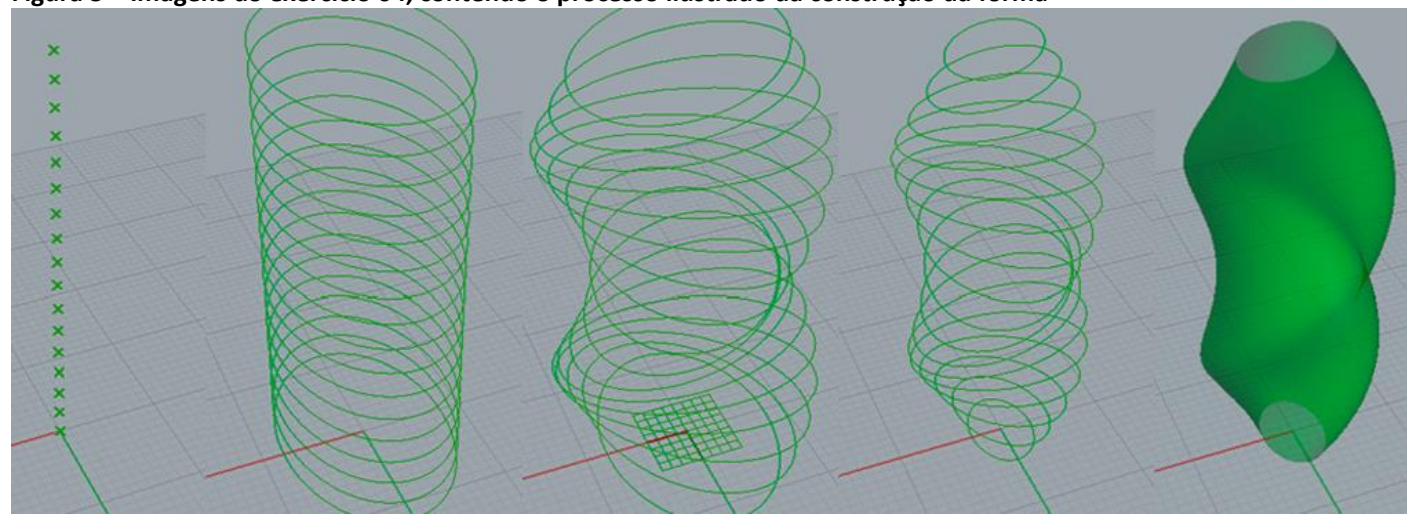

Fonte: Os autores.

Com os exercícios 03 e 04 buscou-se dar início à contextualização dos modelos por meio da aplicação de sua lógica em obras existentes, incluindo uma parede senoidal de tijolos desencontrados, baseada na Iglesia del Cristo Obrero de Eladio Dieste, e uma superfície retorcida a partir da rotação de suas seções, baseada no Turning Tower de Santiago Calatrava. O exercício 03 seguiu a mesma metodologia do 01 e 02, enquanto o exercício 04 (Figura 3) foi inicialmente utilizado para a primeira atividade de leitura e descrição lógica de um objeto. Antes do desenvolvimento do algoritmo, apresentaram-se duas obras que utilizam a mesma lógica do modelo: o Turning Tower (Santiago Calatrava), mencionado anteriormente, e o BBInfo Tower (Kusus + Kusus Architekten). 
Posteriormente, foi solicitado aos participantes que deduzissem e descrevessem a lógica compositiva presente em ambas as obras, por meio de diagramas e croquis. Após a entrega de todos os resultados, a solução foi discutida coletivamente e desenvolvido o algoritmo passo-a-passo, buscando-se demonstrar como soluções diferentes podem partir de uma mesma lógica/modelo.

No que diz respeito ao conteúdo abordado para o ensino do software, deu-se início à introdução de operações unárias de transformação da forma (rotação, translação, escala), utilização de mapas gráficos (graph mapper) e manipulação de dados (listas e séries).

As operações unárias de transformação da forma permitem gerar variações de um mesmo elemento e são comumente encontradas em outras ferramentas digitais, Por outro lado, os mapas gráficos e a manipulação de dados por meio de listas e séries iniciam a introdução de uma das principais características da abordagem paramétrica, verificada em referencial teórico e prático: conceber, organizar e editar dependências/relações por meio do fluxo de dados. Nesse momento, surgem as primeiras dificuldades quanto à mudança na leitura e descrição lógica dos objetos, considerando suas características fixas e variáveis.

Por esse motivo, a partir do exercício 05 em diante, adotou-se sempre a estratégia de apresentar imagens com exemplos de obras que apliquem a lógica adotada no modelo, além de demonstrar o funcionamento geral do algoritmo, antes da sua construção passo-a-passo com os participantes. Dessa forma, buscou-se deixar clara a relação entre a lógica compositiva do objeto, a descrição em algoritmo, as possíveis variáveis do modelo e os exemplos de aplicação em situações práticas.

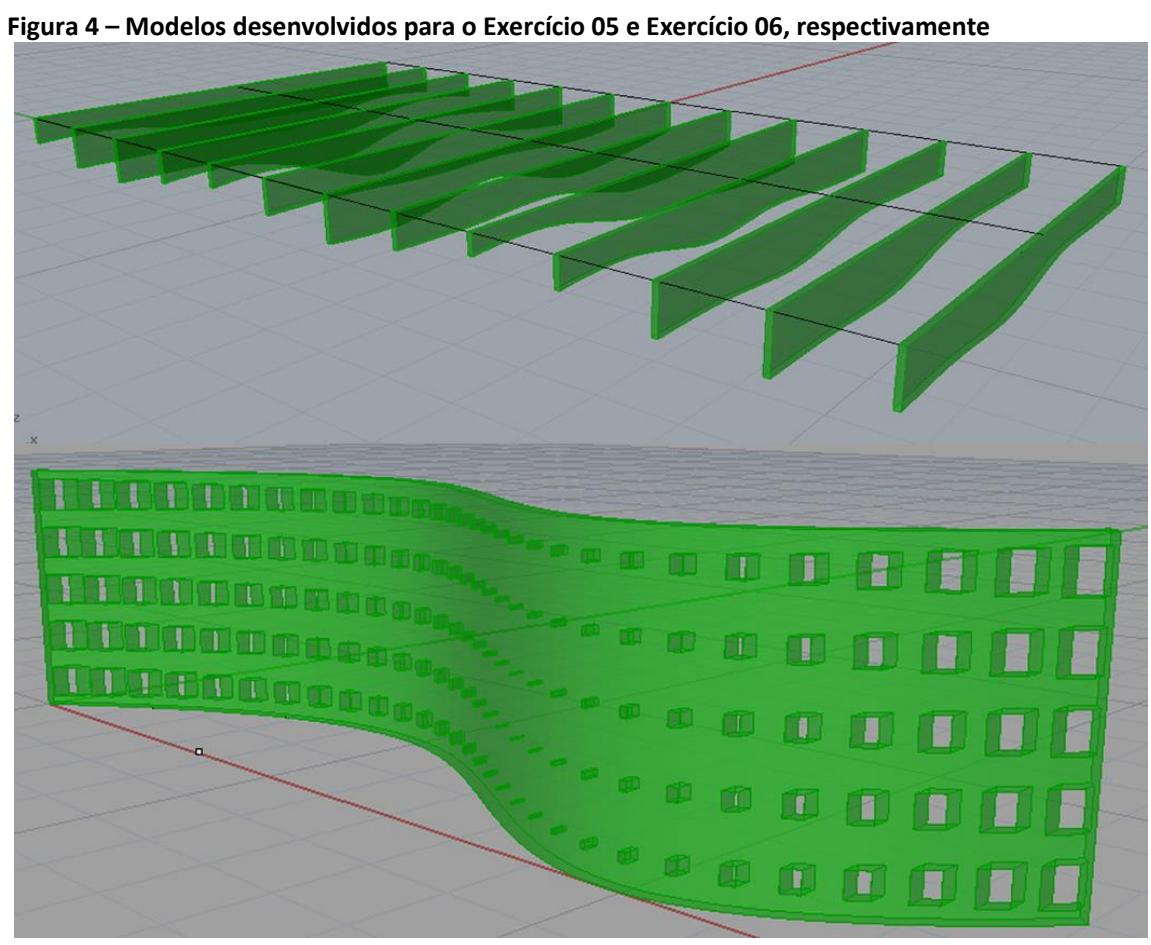

Fonte: Os autores.

Os exercícios 05 e 06 (Figura 4) buscaram aplicar o modelo paramétrico na escala de componentes construtivos e trazer maior complexidade às variáveis: um forro com peças de ondulações independentes e uma parede com desenhos vazados que variavam de acordo com a proximidade em relação a determinado ponto (atrator). Complementando com o exercício 07, buscou-se referências tanto na arquitetura 
quanto no design de produto: um objeto composto por chapas vazadas, a partir da subtração de duas geometrias, baseado na estante Mob (Atelier UM+D) e na intervenção espacial Rest Hole da Universidade de Seoul (UTAA).

O curso teve início com a apresentação dos participantes, incluindo perfil, experiências anteriores e expectativas. Houve uma aula expositiva com o mesmo conteúdo apresentado na palestra, para revisão dos conceitos e possibilidades de aplicação, seguida da introdução ao ambiente de trabalho do software Rhinoceros e seu plug-in Grasshopper.

As divisões de linhas, planos e volumes permitem a criação de novos objetos a partir de existentes, mantendo relações de interdependência por meio de componentes em comum. Já as operações booleanas incluem as operações binárias de transformação da forma de união, subtração e intersecção. Também presentes em outras ferramentas digitais, são fundamentais para a geração de novos elementos, a partir da composição de dois ou mais elementos existentes.

No caso do exercício 06, a superfície que representa a parede foi dividida nos sentidos vertical e horizontal para criar uma quantidade variável de linhas e colunas, A partir dessas divisões foram definidos os volumes que posteriormente foram subtraídos da parede original para criar os desenhos vazados.

O remapeamento de lista de dados é fundamental para transformar os valores de um domínio numérico em valores equivalentes de outro domínio numérico, permitindo estabelecer interdependências entre valores de naturezas diferentes. No caso do exercício 06, o remapeamento de listas foi utilizado para estabelecer uma relação de equivalência entre a distância de um determinado ponto (atrator) e o fator de escala dos desenhos vazados da parede. Assim, à medida que se afasta/aproxima determinado ponto da parede, os vazados sofrem um aumento/redução proporcional de tamanho.

Por fim, a etapa de treinamento do software foi concluída por meio dos exercícios 08 e og em sequência, com a modelagem de um cobogó paramétrico e sua posterior aplicação em uma parede para simulação de sombra (Figura 5).

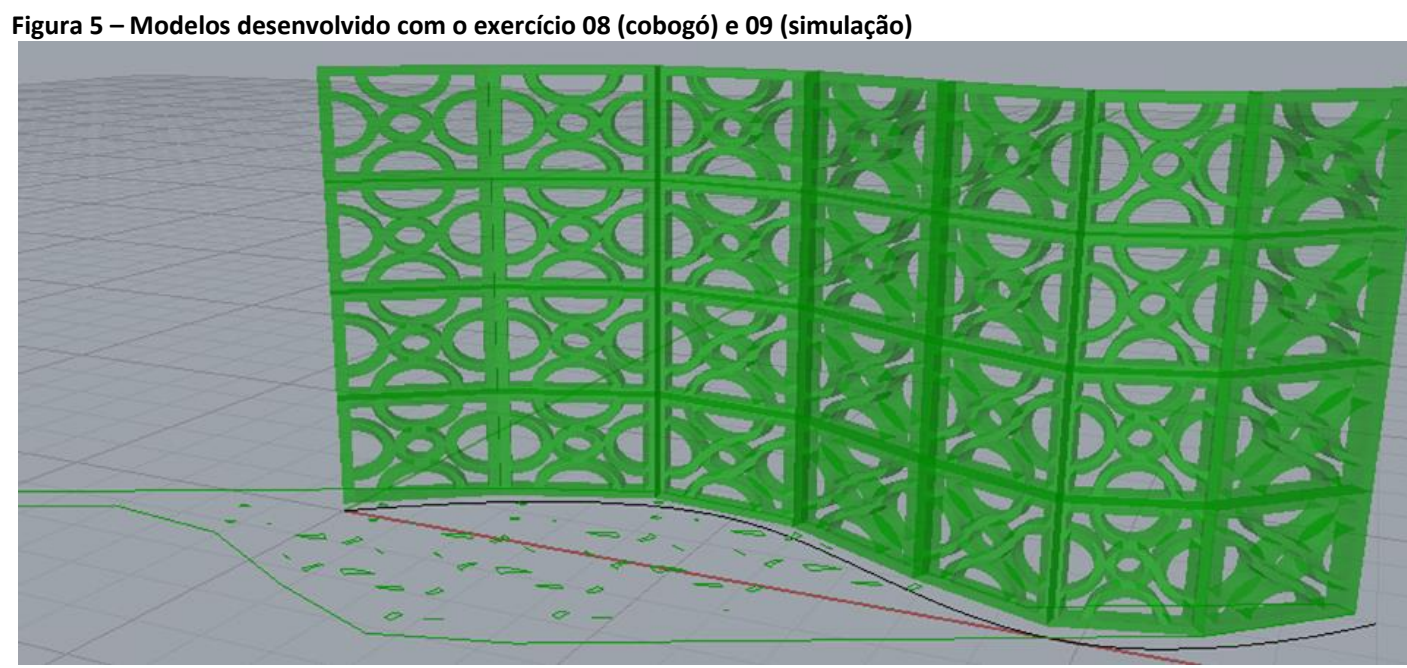

Fonte: Os autores.

Como conteúdo, buscou-se demonstrar o potencial do uso do modelo para a geração de variações de um componente construtivo, e sua posterior avaliação diante de critérios de projeto (insolação x sombreamento). 
Com a conclusão da primeira metade do curso, esperou-se oferecer aos participantes embasamento necessário quanto ao referencial teórico, uso do Grasshopper e mudança da lógica de leitura/descrição de objetos na abordagem paramétrica. Nessa etapa, os exercícios foram individuais com discussão coletiva ao final.

Ressalta-se que, antes da etapa de projeto, os participantes visitaram o LabMaq para conhecerem mais sobre os equipamentos e processos de fabricação, apresentados por um dos professores responsáveis pelo laboratório.

Iniciou-se assim a segunda etapa do curso com as atividades de projeto em atelier, incluindo a apresentação do problema, formação das equipes e brainstorm. O problema de projeto consistiu no desenvolvimento de um bicicletário para o campus da UFRN, devido à pertinência do tema para a instituição, em processo de implementação de estrutura cicloviária, somada à escala coerente com o tempo de curso.

Para auxiliar os participantes, foram disponibilizados manuais técnicos e editais recentes de concurso de ideias envolvendo a problemática, formato de apresentação e quais critérios deveriam ser vislumbrados:

- Área coberta para o espaço das bicicletas;

- Guarda volume;

- Possibilidade de expandir ou replicar, considerando diversas áreas do campus.

Com a desistência de um estudante no $2^{\circ}$ dia do curso, a turma de 19 participantes foi distribuída em 4 equipes. Pela preferência de uma das equipes de trabalhar em dupla, os dois participantes com maior experiência e domínio no uso da modelagem paramétrica foram designados para auxiliar todas as equipes como monitores durante a etapa de atelier. Assim, a turma se dividiu em três equipes de cinco membros, uma dupla e dois monitores.

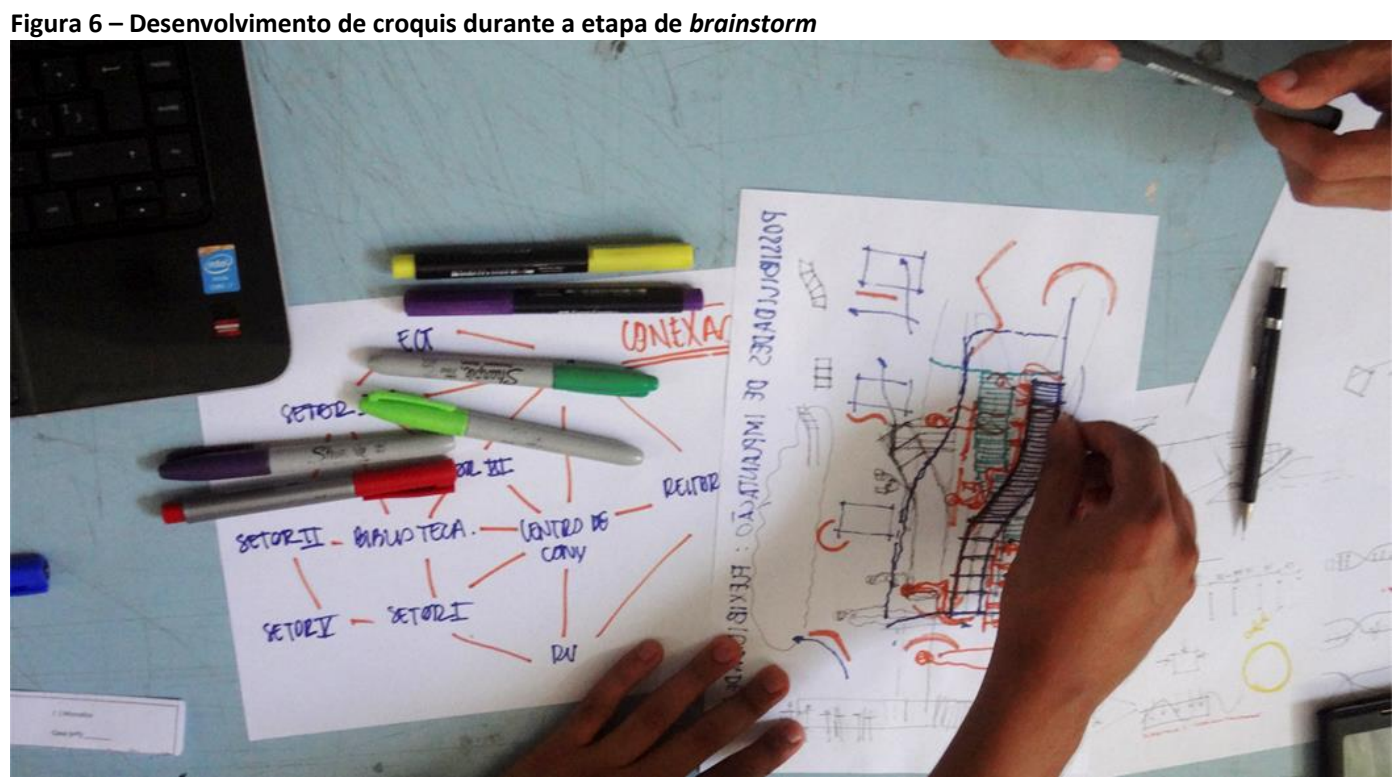

Fonte: Os autores.

Durante a atividade de brainstorm, os participantes foram incentivados a não utilizarem o Grasshopper, trabalhando com conceitos, diagramas e croquis na busca de identificar suas intenções de projeto, características fundamentais e variáveis (Figura 6). Nesse caso, considerou-se tanto a falta de experiência na ferramenta por parte da maioria da turma, quanto a oportunidade de se observar como os participantes se apropriariam do 
pensamento paramétrico para além do uso do software ou uma ferramenta específica. Focou-se na mudança da lógica compositiva e não apenas na ferramenta.

As equipes adotaram estratégias diferentes: enquanto algumas trabalharam a mesma ideia em conjunto, outras incentivaram cada participante a pensar em uma solução individual para depois discutirem em grupo.

Com a definição de conceitos e partidos, as propostas de projeto foram desenvolvidas com uso do modelo paramétrico em atelier. As equipes foram auxiliadas pela instrutora e pelos dois monitores. Não foi possível realizar a apresentação parcial e discussão coletiva, pois utilizou-se todo o tempo das aulas para o próprio projeto.

Por iniciativa dos próprios participantes, algumas equipes também utilizaram o SketchUp e o AutoCad para visualizar a proposta ou desenhar curvas que seriam importadas para o Grasshopper.

Paralelo à orientação em atelier, também foram disponibilizados turnos alternados para a fabricação dos modelos físicos no LabMaq. Durante o curso, apenas a impressora 3D a pó estava disponível no laboratório da instituição, enquanto a cortadora CNC a laser necessitava de reparos. Para auxílio na utilização do equipamento, os participantes contaram com um dos servidores do laboratório, que acompanhou todo o processo de fabricação.

Enquanto as equipes trabalharam no desenvolvimento dos modelos ou montagem da apresentação final, foram realizados testes de impressão do projeto das duas equipes que finalizaram seus modelos paramétricos primeiro. Na Figura 7, é possível observar a confecção do modelo de bicicletário de uma das equipes.

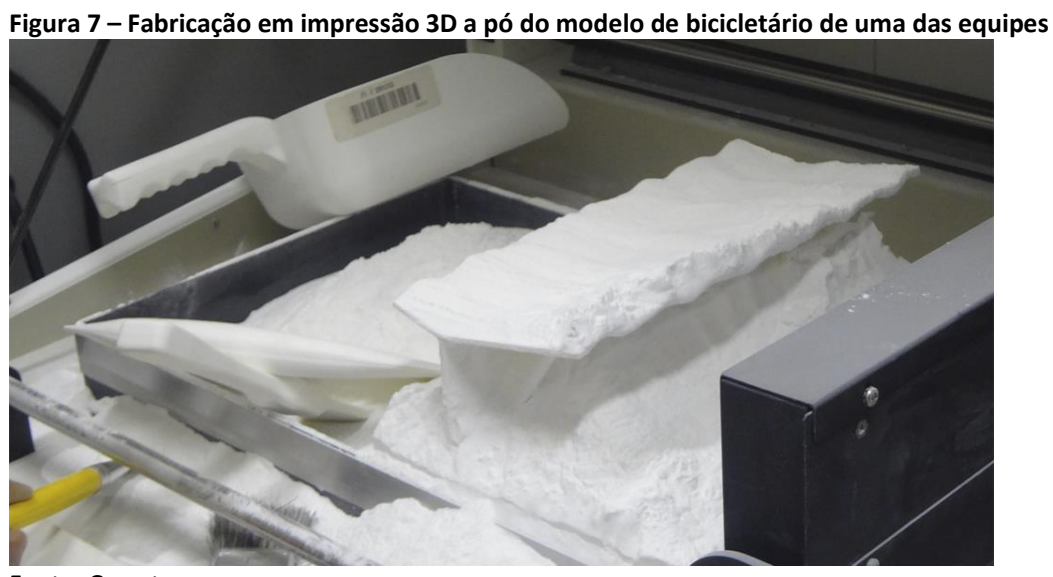

Fonte: Os autores.

Como as soluções envolveram a disposição de perfis, os modelos físicos em pó ficaram com a base fragilizada e quebraram antes de serem completamente retirados da impressora. Percebendo que a impressão 3D poderia não ser a mais adequada para as soluções adotadas pelas equipes, optou-se por não insistir na fabricação para não haver mais perda de material e frustração por parte dos participantes.

Nesse caso, ressalta-se a importância da disponibilidade e compreensão das especificidades dos diferentes equipamentos de fabricação auxiliada por computador, além do apoio à criação e manutenção de laboratórios nas instituições, para que seja possível a inclusão adequada da etapa de materialização à atividade projetual.

O curso encerrou-se com a apresentações das soluções finais, discussão coletiva para feedback dos participantes e aplicação de questionários. Todas as equipes adotaram soluções baseadas na definição de um perfil inicial, que seria disposto ao longo de um 
eixo para a conformação geral dos bicicletários. Foram aplicados parâmetros para variação no próprio perfil e/ou na sua disposição.

A equipe $A$ optou por trabalhar uma estrutura que integrasse o bicicletário a um banco como área de convivência. Houve a intenção de mesclar a forma poligonal do perfil à organicidade da coberta, além de trabalhar a analogia com pergolados. Foram aplicados parâmetros no perfil principal e sua distribuição, com variação da altura, inclinação e pontos que controlam a curva da coberta, altura do banco, espaçamento e quantidade dos perfis.

A equipe $B$ adotou conceitos de modulação e permeabilidade, por meio de um único perfil que contém coberta e bicicletário, gerando uma volumetria fluida a partir de sua rotação. Foram aplicados parâmetros no perfil principal e em sua distribuição, com possibilidade de variação na curva de distribuição, espaçamento, quantidade de perfis, rotação dos perfis no plano $\mathrm{YZ}$ e espessura de cada perfil. $O$ resultado final das equipes A e $B$ podem ser vistos na Figura 8.
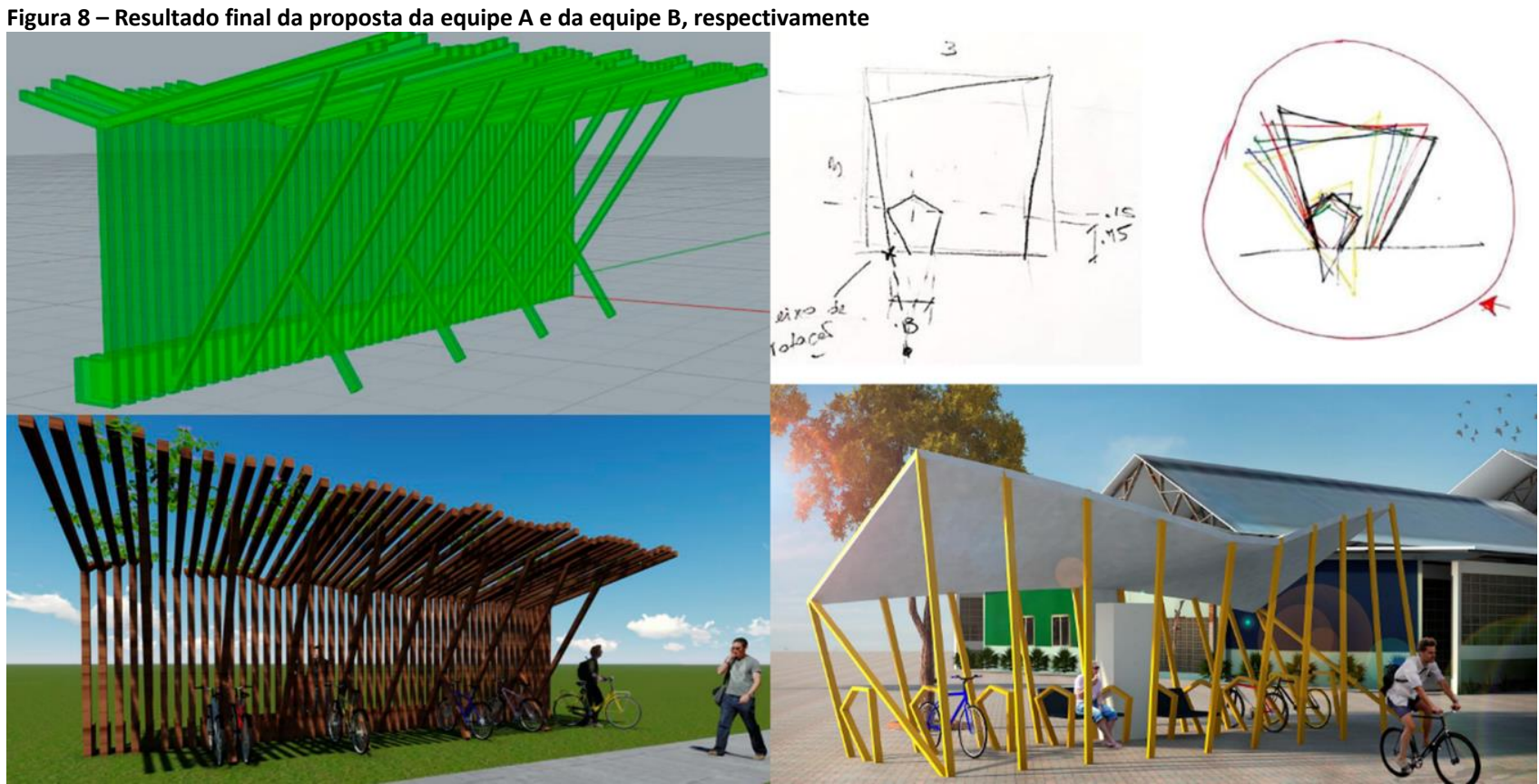

Fonte: Os autores.

A equipe $C$ propôs um perfil que pudesse ser fixado a elementos construtivos existentes, como postes e muros, através de uma curva para compor tanto o bicicletário quanto a coberta. Como parâmetros, o trecho do bicicletário poderia sofrer rotação para se adequar a diferentes alturas de bicicleta, enquanto a curva de distribuição do perfil poderia se adequar a diferentes elementos construtivos.

A equipe $D$ trabalhou a concordância de curvas em um mesmo perfil, onde a curva referente à coberta poderia sofrer rotação, em função da necessidade de proteção solar; enquanto a curva do bicicletário se manteria estática, porém, com possibilidade de diferentes distanciamentos para a composição de bancos em determinados trechos. A composição final também buscou o efeito de movimento. O resultado final das equipes $C$ e $D$ podem ser vistos na Figura 9. 
ROMCY, Neliza Maria e Silva; CARDOSO, Daniel Ribeiro

A introdução da abordagem paramétrica no ensino de projeto arquitetônico: relato de uma experiência

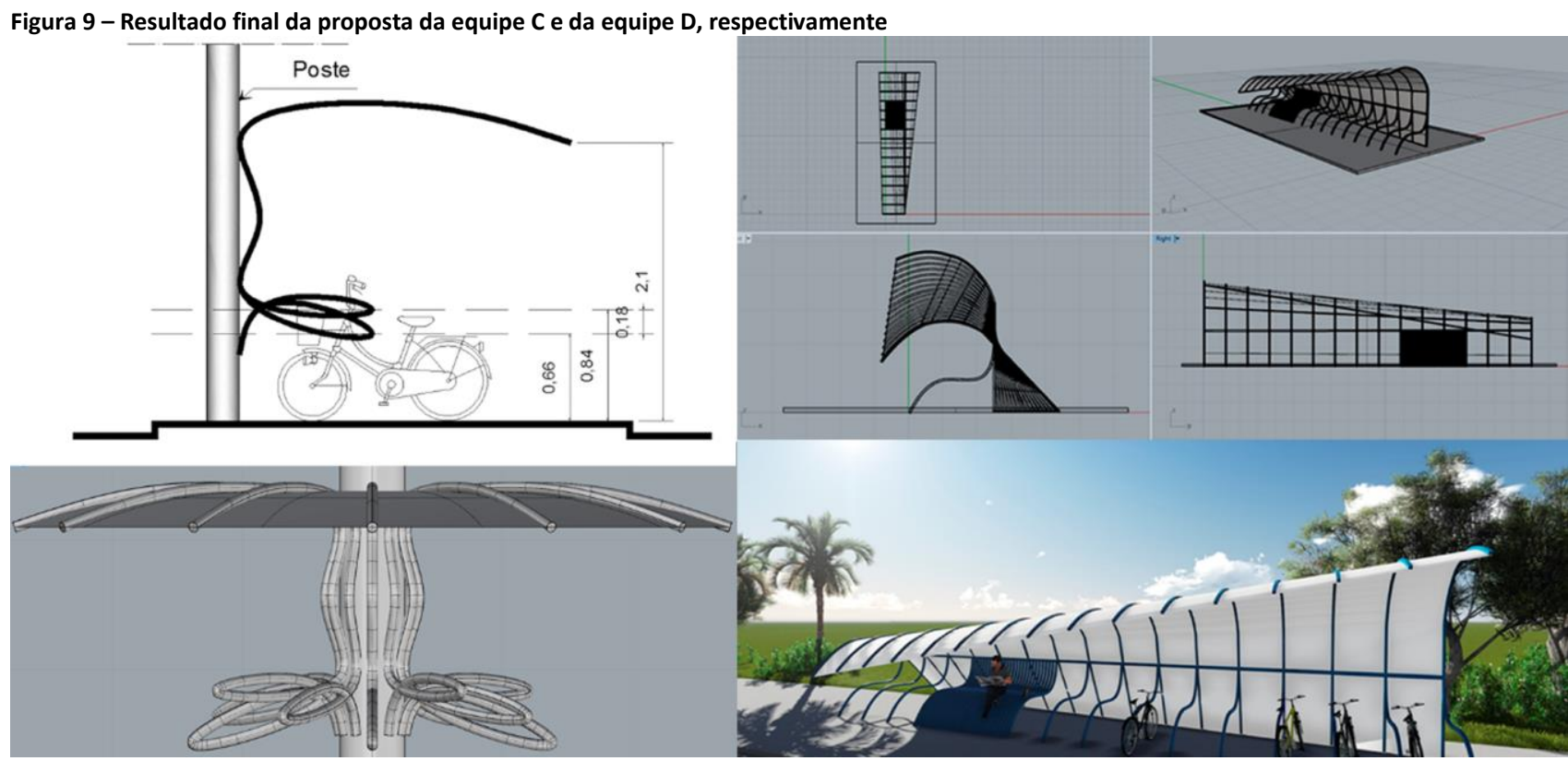

Fonte: Os autores.

\section{Resultados e discussão}

Ao longo das apresentações, três equipes registraram em suas considerações finais as contribuições e dificuldades percebidas no uso da modelagem paramétrica, colaborando com a coleta de dados. O Quadro 1 apresenta tais comentários, que foram acrescentados às observações e resultados dos questionários para a análise final do curso. Os questionários, aplicados no último dia de curso, contaram com a resposta dos 19 participantes, atingindo uma amostragem de $100 \%$.

Quadro 1 - Considerações finais registradas nas apresentações de 3 das 4 equipes que participaram do curso Considerações - sobre o processo de projeto

Dificuldade de concretizar o projeto, devido ao processo de concepção do Grasshopper; Importância da maquete para a execução das estruturas;

Importância da parametrização dentro do processo de projeto, conferindo uma maior liberdade ao projetista com um menor dispêndio de tempo.

\begin{tabular}{|c|c|}
\hline \multicolumn{2}{|c|}{ Considerações - sobre as habilidades } \\
\hline Dificuldades & Benefícios \\
\hline $\begin{array}{l}\text { Pensar desconstruindo a forma } \\
\text { Projetar em novo programa } \\
\text { Traduzir o raciocínio em algoritmos } \\
\text { Curso de curta duração }\end{array}$ & $\begin{array}{l}\text { Nova maneira de pensar e projetar } \\
\text { Aprendizado de nova ferramenta } \\
\text { Possibilidade de criação de novas formas projetuais }\end{array}$ \\
\hline \multicolumn{2}{|c|}{ Considerações - sobre as ferramentas } \\
\hline $\begin{array}{r}\text { Uma ferramenta de grande potencial para o proc } \\
\text { Possibilita estudos de aspectos } \\
\text { O uso do programa exige conhecimento de } p \\
\text { A dificuldade de mensu } \\
\text { Não elimina outros }\end{array}$ & $\begin{array}{l}\text { pecialmente de formas complexas, ao mesmo tempo em } \\
\text { formais. } \\
\text { tura, iluminação natural entre outros. } \\
\text { cional que tornou um desafio para nossa concepção. } \\
\text { as, formas bidimensionais etc). } \\
\text { ão, seja tradicional ou não. }\end{array}$ \\
\hline
\end{tabular}

Fonte: Os autores.

Sobre a caracterização geral dos participantes, o curso contou com 10 profissionais, compreendendo dois projetistas, dois docentes, três mestrandos e dois doutorandos. Dentre os estudantes de graduação, 8 eram do curso de arquitetura e 1 do curso de design. É importante ressaltar que, como pré-requisito para inscrição, os estudantes de arquitetura precisavam ter concluído o $5^{\circ}$ semestre e os de design $04^{\circ}$ semestre, pois 
considera-se a conclusão das disciplinas de informática aplicada ao processo de projeto de cada currículo.

Quanto a experiências anteriores, $47 \%$ afirmaram ter tido algum contato anterior com modelagem paramétrica, sendo mencionadas disciplinas (10,5\%), curso (10,5\%), workshops (5\%) e outros (21\%). Pressupõe-se que as respostas indicando disciplinas se referem a disciplina de "Desenho Auxiliado por Computador 02", em que os estudantes são instrumentalizados em BIM aprendendo a ferramenta Revit, visto que ainda não há disciplina específica sobre o assunto no curso de Arquitetura e Urbanismo desta instituição. Em relação ao campo "outros", foram mencionados "autodidata em BIM", "tutoriais", "fase da pesquisa" e "palestra". Nesse caso, é importante ressaltar a pressuposição de que pelo menos três respondentes (16\%) colocaram ter experiência em BIM, não modelagem paramétrica propriamente dita.

Para ilustrar a caracterização geral dos 19 participantes, a Figura 10 apresenta o quantitativo quanto à natureza da ocupação, enquanto a Figura 11 apresenta a experiência anterior.
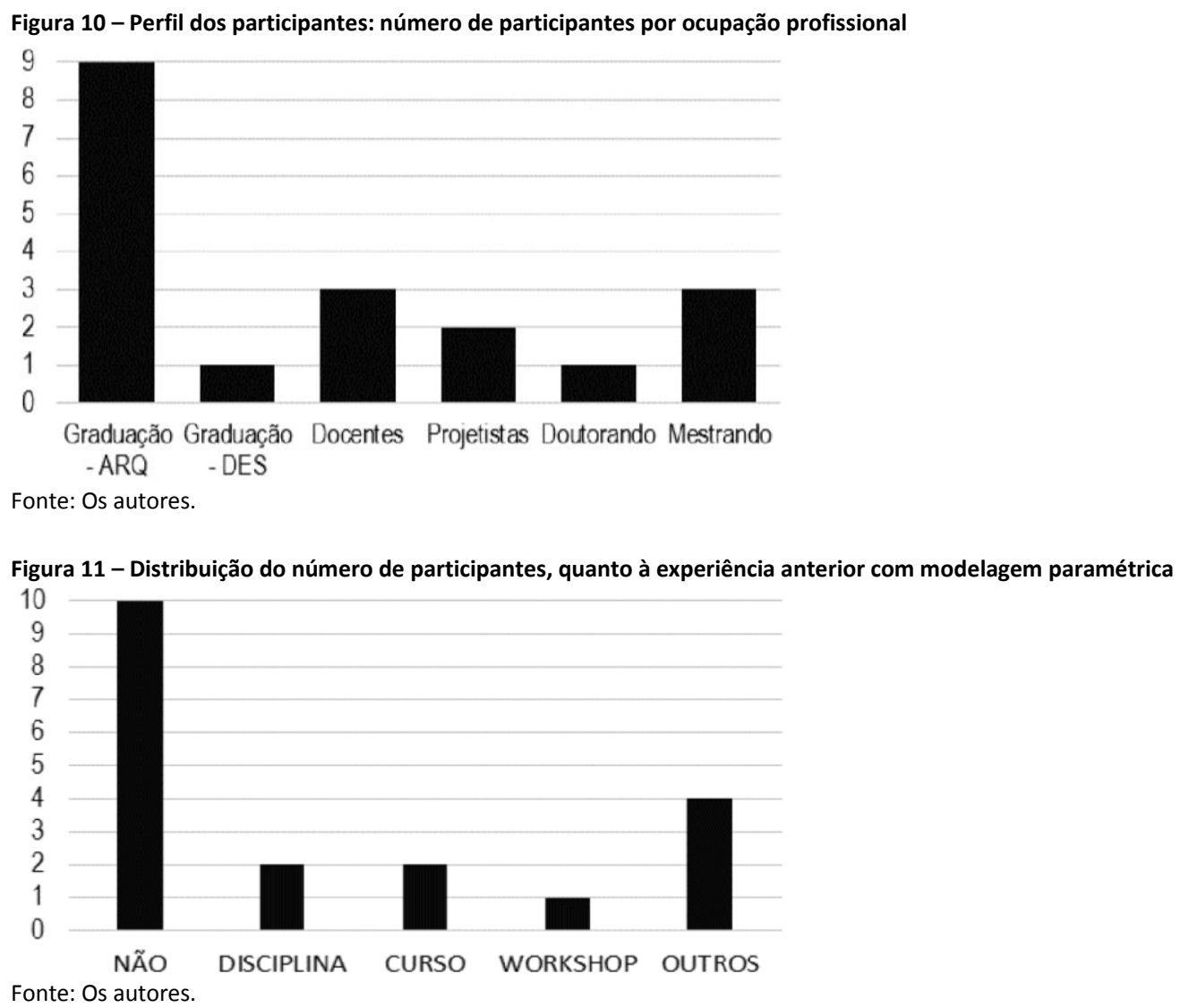

Sobre as atividades do curso, foram calculadas as médias para a nota que os participantes atribuíram para cada item, apresentadas no Quadro 2, por ordem decrescente. Manteve-se a numeração antes da descrição do item para facilitar sua identificação na lista do questionário. Ressalta-se que o item 6 , sobre o uso de fabricação do modelo físico, não foi considerado por não ter sido realizado com êxito durante o curso.

Considerando as notas atribuídas pelos participantes, é importante ressaltar que, mesmo para uma turma com pouca experiência em modelagem paramétrica, a importância da aplicação em atelier foi reconhecida (9,32), pois apenas na prática é 
possível enfrentar o problema de projeto e lidar com as dúvidas próprias da aplicação da nova ferramenta/lógica na atividade projetual.

Quadro 2 - Médias das notas atribuídas pelos participantes para cada atividade realizada no curso, em ordem decrescente
\begin{tabular}{|l|c|}
\hline \multicolumn{1}{|c|}{ Descrição da atividade } & Média \\
\hline $\begin{array}{l}|c| \\
\text { 1. Apresentação inicial de conceitos e exemplos de aplicação na arquitetura e design. }\end{array}$ & 9,32 \\
\hline $\begin{array}{l}\text { 5. Atividade de desenvolvimento de projeto em equipe, para que os participantes busquem aplicar a } \\
\text { modelagem paramétrica em uma situação prática. }\end{array}$ & 9,16 \\
\hline $\begin{array}{l}\text { 3. Apresentação da lógica geral do algoritmo e aplicação em exemplos, antes do desenvolvimento passo- } \\
\text { a-passo. }\end{array}$ & 9,05 \\
\hline $\begin{array}{l}\text { 2. Desenvolvimento do algoritmo passo-a-passo, com a explicação geral de cada componente. } \\
\text { 4. Apresentação do objeto para que os participantes tentem descrever a sua lógica de formação através } \\
\text { de desenhos esquemáticos. }\end{array}$ & 8,89 \\
\hline
\end{tabular}

Fonte: Os autores

Em relação à estratégia de ensino da ferramenta/lógica, novamente destaca-se a importância de mostrar a lógica geral do algoritmo e da aplicação em exemplos práticos antes de ensinar apenas o passo-a-passo e a função dos componentes. Por fim, as médias apresentadas no Quadro 2 mostraram notas satisfatórias (9,32-8,89), o que demonstra uma boa aceitação das atividades e da estratégia didática proposta pelo curso.

Sobre as pretensões de uso no futuro, a maioria dos participantes afirmaram ter interesse em continuar trabalhando com a modelagem paramétrica, com apenas uma resposta negativa para 18 positivas, o que representa 95\% de adesão à modelagem paramétrica.

As justificativas para as respostas positivas incluíram tanto a intenção de aplicar a modelagem paramétrica em experiências pessoais, como pesquisa de doutorado, ensino em disciplinas de geometria e projeto; quanto o reconhecimento de características positivas na abordagem paramétrica, como liberdade formal, formas complexas, variedade de alternativas no estudo de soluções, simulação (desempenho térmico, luminoso e estrutural) e novas maneiras de pensar.

Sobre as dificuldades, a maioria das respostas incluiu a lógica ou raciocínio paramétrico, devido à necessidade de "desconstrução da forma e reconstrução através do algoritmo" (68\%); seguido do uso do software (32\%) e do pouco tempo de curso para a quantidade de conteúdo (26\%). Apenas um respondente afirma não ter tido dificuldades, por questão de experiência.

Por fim, as sugestões mais recorrentes colocadas pelos participantes incluíram maior duração do curso ou maior duração de alguma atividade específica, como exercícios de programação, exercícios de leitura de lógica, apresentação inicial do software e etapa de fabricação. Não houve um consenso ou recorrência na indicação de qual atividade necessitaria de maior tempo, portanto a única tendência percebida é a consideração de que a carga horária foi insuficiente para abranger todo o percurso proposto e que todo ele foi importante para o aprendizado do tema. Assim, as principais dificuldades estão relacionadas à mudança na lógica projetual e uso da ferramenta, associadas à carga horária reduzida para todo o percurso didático necessário - da introdução do tema ao atelier.

\section{Conclusão}

Com a aplicação do experimento pedagógico do curso de extensão, foi possível reforçar aspectos colocados no referencial teórico e avaliar estratégias para a introdução da abordagem paramétrica no ensino de projeto. Os resultados dos questionários e da 
observação em sala apontam como principais desafios, não só o aprendizado da ferramenta, mas principalmente o domínio da lógica paramétrica, presentes durante a estruturação da ideia em algoritmo, isto é, do pensamento algorítmico. De fato, o pensamento algorítmico já havia sido mencionado no referencial teórico (WOODBURY, 2010) como uma habilidade que os projetistas devem desenvolver para aplicar a modelagem paramétrica de maneira efetiva.

Como uma análise geral percebe-se que, apesar da maioria da turma não ter experiência com o tema, os resultados são satisfatórios, com o desenvolvimento e investigação de algoritmos complexos, avaliações positivas na contribuição das atividades propostas para o aprendizado sobre o tema, além do reconhecimento do potencial da modelagem paramétrica e pretensões de aplicação no futuro.

Também são percebidas dificuldades quanto ao uso dos laboratórios de fabricação, como manutenção e especificidades dos equipamentos. Durante o curso, utilizou-se a impressora 3D a pó, devido à indisponibilidade da cortadora a laser por questões técnicas. Porém, as características de seu processo de fabricação (adição de camadas de pó e cola) não são as mais adequadas para uma solução em perfis, de espessura delgada, levando à fragilidade do objeto. Para tanto, o mais adequado seriam processos em corte (subtrativos) que utilizassem a própria espessura do material para representar a espessura do perfil. Embora se pudesse ter tentado a impressão apenas da volumetria geral de cada solução, não seria possível analisar as principais questões de cada proposta, como estrutura e adequação dos bicicletários. Deve-se considerar a integração e contribuição mútua entre o modelo paramétrico e outros meios, tanto analógicos, como croquis e diagramas, quanto equipamentos de fabricação auxiliada por computador, em um processo projetual contínuo que vai da concepção à materialização.

As principais dúvidas percebidas ao longo da atividade projetual incluem: a) quais características do projeto devem ser transformadas em variáveis; b) como organizar o fluxo de informações para atingir o resultado desejado (algoritmo); c) em que momento dar início ao modelo paramétrico para que ele traga uma real contribuição ao processo de projeto, ao invés de ser uma mera ferramenta de desenho.

Em resumo, o desenvolvimento das habilidades requisitadas pelo processo paramétrico de projeto envolve diversos aspectos que exigem tempo, exercício e experiência quanto a: (i) domínio das ferramentas, (ii) compreensão do pensamento algorítmico/paramétrico e sistêmico, (iii) aplicação prática em problemas de projeto, (iv) interfaces com outros meios, como o croqui e a fabricação auxiliada por computador.

Nesse caso, reforça-se a hipótese de que apenas o ensino tutorial de ferramentas não é o suficiente para uma aprendizagem do processo paramétrico em todo o seu potencial, ressaltando-se a importância de que o percurso didático vislumbre tanto uma mudança de olhar sobre o objeto projetado - a partir de uma lógica paramétrica - quanto a própria atividade projetual em atelier.

Para enfrentar esse desafio, é importante associar o desenvolvimento de algoritmos em sala de aula com o exercício de descrição da lógica compositiva dos objetos a serem representados, a partir de suas partes e relações (visão sistêmica), além de incluir o desenvolvimento de uma atividade prática de projeto em atelier. As altas notas dadas pelos participantes à contribuição de todas as atividades desenvolvidas no curso de extensão (com médias entre 9,32 e 8,89) demonstram o reconhecimento da importância desse ensino gradativo e que envolvem, no mínimo, habilidades envolvidas na área de percepção da forma, representação e projeto. 
Para contemplar de maneira satisfatória todo esse percurso, percebe-se que a carga horária de um curso de extensão, neste caso de englobando o total de 60 horas, assim como uma disciplina não é o ideal. Este fato foi observado tanto durante o percurso do experimento didático (com a necessidade de adequações para o que havia sido previsto na etapa de atelier) quanto nas sugestões dadas pelos próprios participantes. Assim, pressupõe-se a necessidade de se investigar a introdução da abordagem paramétrica para além de um experimento didático isolado, com a análise da estrutura curricular de cursos de arquitetura e design, buscando identificar em que áreas de conhecimento o tema pode ser inserido. Essa ampliação do debate traz possibilidades não só de aumentar a carga horária para o ensino/aprendizagem sobre o tema, como também refletir sobre as possibilidades de contribuição da abordagem paramétrica em diferentes áreas de conhecimento, exercitando uma visão pedagógica mais colaborativa e integrada.

\section{Agradecimentos}

À Coordenação de Aperfeiçoamento de Pessoal de Nível Superior (CAPES), pela bolsa de Doutorado concedida. Ao professor Dr. Marcelo Tinoco, in memoriam, pela orientação e acompanhamento durante toda a Tese. À professora Dra. Maísa Veloso, pela orientação e acompanhamento durante a fase de conclusão da pesquisa.

\section{Referências}

ANDRADE, M.L.V.X.; RUSCHEL, R.C. BIM: Conceitos, cenário das pesquisas publicadas no Brasil e tendências. In: SIMPÓSIO BRASILEIRO DE QUALIDADE DO PROJETO NO AMBIENTE CONSTRUÍDO, 2009, São Carlos. Anais [...]. São Carlos: Rima Editora, 2009. p. 602-613. DOI: https://doi.org/10.4237/sbqp.09.166

BEIRÃO, J. N. Sobre o ensino da Arquitectura e o futuro profissional do Arquitecto - O Papel da Arquitectura nas sociedades criativas. J-A Jornal Arquitectos. Fórum. Crônicas. 2014. Disponível em:

http://www.jornalarquitectos.pt/pt/forum/cronicas/sobre-o-ensino-da-arquitetura-e-o-futuro-profissional-doarquiteto. Acesso em: junho de 2017.

FLORIO, W. Notas sobre pensamento e cognição em projetos paramétricos. In: ENCONTRO DA ASSOCIAÇÃO NACIONAL DE PESQUISA E PÓS-GRADUAÇÃO EM ARQUITETURA E URBANISMO, 2, 2012, Natal. Anais [...]. Natal: ENANPARQ, 2012.

GIL, A. C. Como elaborar projetos de pesquisa. $4^{\text {a }}$ edição. Editora Atlas. 2002.

KOLAREVIC, B. Designing and manufacturing architecture in the digital age. Architectural information management, 2001.

KOLAREVIC, B. Architecture in the Digital Age: design and manufacturing. New York; London: Taylor \& Francis, 2003.

LAWSON, B. Como arquitetos e designers pensam. São Paulo: Oficina de Textos, 2011.

NOJIMOTO, C.; TRAMONTANO, M; ANELLI, R.L.S. Design Paramétrico: Experiência Didática. In: XV CONGRESO DE LA SOCIEDAD IBEROAMERICANA DE GRAFICA DIGITAL, 15., 2011, Santa Fé. Proceedings [... ]. Santa Fé: SIGraDI, 2011. p. 456-460.

OXMAN, R. Theory and design in the first digital age. Design Studies, v. 27, n. 3, 2005. p. 229-265. DOI:https://doi.org/10.1016/j.destud.2005.11.002

OXMAN, R. The new structuralism Design, Engineering and Architectural Technologies. New Jersey: John Wiley \& Sons, 2010. 
ROMCY, Neliza Maria e Silva; CARDOSO, Daniel Ribeiro

A introdução da abordagem paramétrica no ensino de projeto arquitetônico: relato de uma experiência

PRODANOV, C. C., FREITAS, E. C. Metodologia do trabalho científico: métodos e técnicas da pesquisa e do trabalho acadêmico. 2. ed. Novo Hamburgo: Feevale, 2013.

ROCHA, I. A. M. Programa e projeto na era digital: o ensino de projeto de arquitetura em ambientes virtuais interativos. Tese (Doutorado) - Programa de Pós-graduação em Arquitetura da UFRGS, Porto Alegre, 2009.

ROMCY, N. M. S. Introdução da Abordagem Paramétrica no Ensino de Projeto: resultados de uma experiência. In: SIMPÓSIO DE PESQUISA DO PPGAU-UFRN - DOUTORADO, MESTRADO ACADÊMICO E MESTRADO PROFISSIONAL, 4., 2016, Natal. Anais [...]. Natal:UFRN, 2016.

SCHÖN, D. Educando o Profissional Reflexivo: um novo design para o ensino e a aprendizagem. Porto Alegre: Editora Artmed, 2000.

SEDREZ, M.; CELANI, G. Ensino de projeto arquitetônico com a inclusão de novas tecnologias: uma abordagem pedagógica contemporânea. Pós - Revista do Programa de Pós-Graduação em Arquitetura e Urbanismo da FAUUSP, v.21, 2014. p. 78-97. DOI: https://doi.org/10.11606/issn.2317-2762.v21i35p78-97

SOARES, J.P, TRAMONTANO, M. Arquitetura emergente, design paramétricos e o representar através de modelos de informação. V!RUS, São Carlos, n. 8, dezembro 2012.

WOODBURY, R. Elements of parametric design. Routledge, 2010.

\section{${ }^{1}$ Neliza Maria e Silva Romcy}

Arquiteta e Urbanista. Doutorado. Endereço postal: Departamento de Arquitetura, Urbanismo e Design da Universidade Federal do Ceará. Av. da Universidade, 2890, Benfica, Fortaleza, CE, Brasil, CEP: 60020-181.

\section{Daniel Ribeiro Cardoso}

Arquiteto e Urbanista. Pós-doutorado. Endereço postal: Departamento de Arquitetura, Urbanismo e Design da Universidade Federal do Ceará. Av. da Universidade, 2890, Benfica, Fortaleza, CE, Brasil, CEP: 60020-181. 